JPE 10-3-7

\title{
Identification of DC-Link Capacitance for Single-Phase AC/DC PWM Converters
}

\author{
Xing-Si Pu*, Thanh Hai Nguyen*, Dong-Choon Lee ${ }^{\dagger}$, and Suk-Gyu Lee* \\ $\dagger^{*}$ Dept. of Electrical Engineering, Yeungnam University, Korea
}

\begin{abstract}
In this paper, a capacitance estimation scheme for DC-link capacitors for single-phase AC/DC PWM converters is proposed. Under the no-load condition, a controlled AC current $(30[\mathrm{~Hz}])$ is injected into the input side, which then causes AC voltage ripples at the DC output side. Or, a controlled AC voltage can be directly injected into the DC output side. By extracting the AC voltage/current and power components on the DC output side using digital filters, the capacitance value can be calculated, where the recursive least squares (RLS) algorithm is used. The proposed methods can be simply implemented with software only and additional hardware is not required. From the experiment results, a high accuracy estimation of capacitances less than $0.85 \%$ has been obtained.
\end{abstract}

Key Words: Capacitance estimation, Digital filter, PR-controller, PWM converters

\section{INTRODUCTION}

These days, single-phase AC/DC PWM converters are widely used for the grid connection of renewable energy conversion systems such as photovoltaic (PV) and fuel cells, and UPSs (uninterruptible power systems) [1], [2]. Electrolytic capacitor banks are usually used for these types of converters as an energy buffer. By the aging effect, the capacitor banks lose their initial characteristic due to the electrolytic reaction, effects of temperature and humidity, and some unstable factors in the system. This results in a decrease of capacitance (C) and an increase of equivalent series resistance (ESR) [3]. Therefore, it is necessary to indentify by what percent the capacitance has been reduced or by what percent the ESR has been increased and when it should be replaced by new one.

The capacitor banks are usually installed in the interior of converter systems. Therefore, it is hard to measure the capacitance with LCR meters. To overcome this difficulty, an algorithm based on the loss of the electrolyte of the capacitor, which results in a decrease in capacitor weight, has been proposed [4]. If the volume of the electrolyte is reduced by more than $40 \%$, the lifetime of the capacitor is considered to be ended. However, this method is also inconvenient since capacitors needs to be disconnected from the system for measurement. On the other hand, a method that involves the measuring of gas pressure inside an electrolytic capacitor has been proposed to estimate its lifetime [5]. However, this method is too complex and requires a few hours of measurement due to chemical processing.

\footnotetext{
Manuscript received Jan. 6, 2010; revised Mar. 17, 2010

$\dagger$ Corresponding Author: dclee@yu.ac.kr

Tel: +82-53-810-2582, Fax: +82-53-810-4767, Yeungnam Univ.

* Dept. of Electrical Eng., Yeungnam University, Korea
}

Since the ESR of an electrolytic capacitor is increased with aging, its deterioration can be determined by measuring the change in ESR [6]- [10]. For a buck-boost and forward DC/DC converters, an analytic relationship between the capacitor current and voltage was used to estimate the ESR value, and this approach has been successfully applied to these kinds of converters [6]. Also, another method was proposed, which determines if the ESR has increased more than five times its initial value in the electrolytic capacitors used for LC filters of switching mode power converters [7]. This scheme requires additional hardware for processing the measured capacitor voltage. Another ESR estimation method based on the computation of the power loss in a capacitor was proposed in [8], where some additional sensors are required together with a simple analog circuit for signal processing. In [9], an ESR and C estimation method for the DC-link capacitors of PWM inverters was proposed, where no additional hardware is required and the estimation accuracy is less than 5\%. However, the switching frequency and duty cycle of the switching device for testing should be selected carefully. In [10], another ESR and $\mathrm{C}$ identification scheme for the output DC capacitor in a buck converter was proposed, where a state observer was been used. The estimation accuracy of the ESR was less than $6 \%$ and that of $\mathrm{C}$ was not provided. On the other hand, online capacitance estimation methods for three-phase AC/DC/AC PWM converters have been proposed in [11], [12], which give a high accuracy and the advantage of no additional sensors.

The objective of this paper is to propose an algorithm to estimate the DC-link capacitance of single-phase AC/DC PWM converters, from which the deterioration of the capacitor can be diagnosed online. First, an AC current component at lower frequency $(30[\mathrm{~Hz}])$ than the line frequency is injected into the 


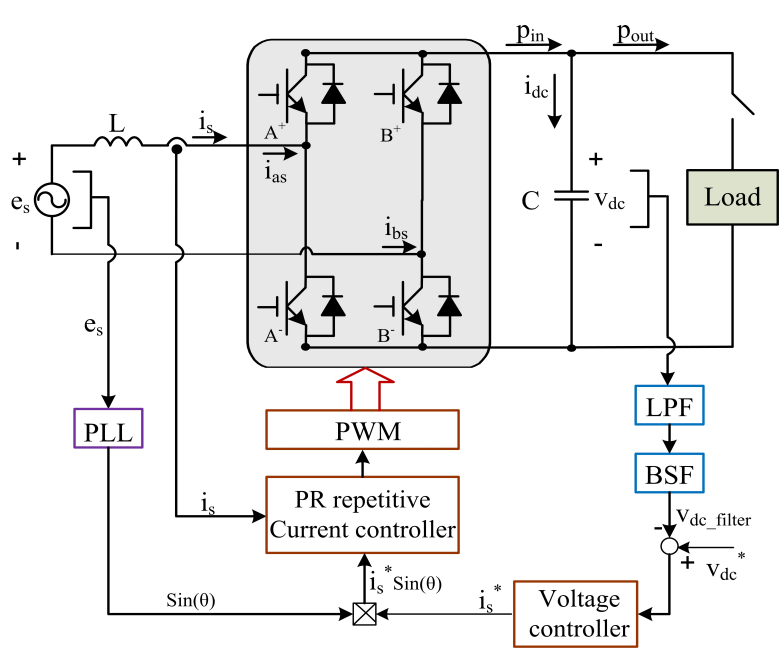

Fig. 1. Control block diagram for single-phase AC/DC PWM converters.

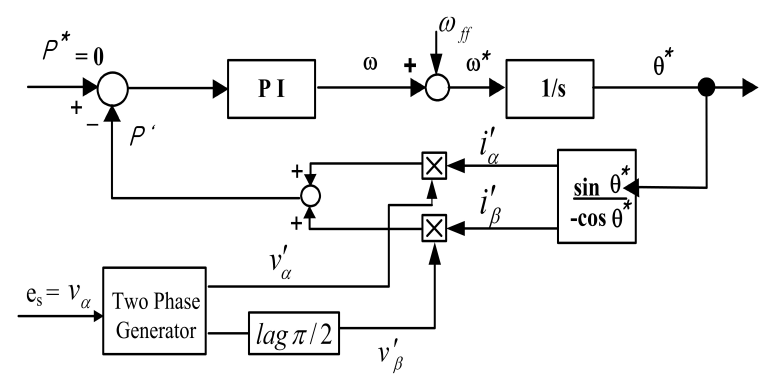

Fig. 2. A structure of single-phase PLL algorithm.

input side, which causes an $\mathrm{AC}$ voltage ripple component in the DC output side. By using a band-pass filter (BPF), the corresponding $\mathrm{AC}$ current and voltage components from the DC output side are extracted. Then, the capacitance value can be estimated using the recursive least squares. In addition, by injecting the AC voltage component into the DC output side, the capacitance can be calculated from the AC voltage and power components in a similar way. From the experimental results, the high accuracy of estimation are obtained less than $0.85 \%$ for both the AC current and voltage injection cases.

\section{CONTROL OF OF AC/DC PWM CONVERTERS}

Fig. 1 shows the power circuit of a single-phase AC/DC PWM converter and its control block diagram, where PI voltage controllers and PR (proportional and resonant) repetitive current controllers are used.

\section{A. Single-Phase PLL (Phase-Locked Loop) Algorithm}

To detect the phase angle of the voltage varying in a sinusoidal waveform, a PLL algorithm is needed, by which a reference frame for control is determined.

A phase angle detection method applied to a single-phase utility systems was described in [13], based on the modified three-phase instantaneous reactive power theory (p-q theory), the structure of which is shown in Fig. 2. As an input signal of a PLL block, the measured source voltage $e_{s}$ is set to be $v_{\alpha}\left(v_{\alpha}=v_{\alpha}^{\prime}\right)$ in the $\alpha \beta$-coordinate. A phase delay of $\pi / 2$ in $e_{s}$ produces a signal of $v_{\beta}^{\prime}$, which is generated by the twophase generator. Similar to the three-phase PLL structures, the fictitious currents $i_{\alpha}^{\prime}$ and $i_{\beta}^{\prime}$ are made to be orthogonal to the voltages $v_{\alpha}^{\prime}$ and $v_{\beta}^{\prime}$, respectively. To make a delay of $\pi / 2$ in the source voltage $e_{s}$, an all-pass filter is used for a two-phase generator. Its transfer function is given as:

$$
H_{A P F}(s)=\frac{s^{2}-2 \zeta \omega_{n} s+\omega_{n}^{2}}{s^{2}+2 \zeta \omega_{n} s+\omega_{n}^{2}}
$$

where $\xi$ is a damping ratio, which is set to 1 and $\omega_{n}$ is the source frequency. In Fig. 2, $\omega_{f f}$ is a feed-forward frequency component given by the source voltage.

\section{B. PR Repetitive Current Controller}

The performance of a conventional PI current controllers is not so good in single-phase AC systems if the gains are not very high. The excessively high gains usually make the controller sensitive to noise and unstable. To avoid this problem, PR controllers are utilized, which are equivalent to the synchronous d-q axis controllers utilized in three-phase systems [14].

In this paper, the PR controllers are employed for the precise current control of a single-phase PWM converter. The design strategy is based on transforming a desired DC compensation quantity into an equivalent $\mathrm{AC}$ compensation quantity, so that it has the same frequency response characteristic as synchronous PI controllers in the bandwidth of concern. The transfer function of the PR controllers can be expressed as [15]:

$$
H_{P R}(s)=K_{P}+K_{I} \frac{s}{s^{2}+\omega^{2}}+K_{I h} \frac{s}{s^{2}+(h \omega)^{2}}
$$

where, $K_{P}$ is the proportional gain, $K_{I}$ is the integral gain, $K_{I h}$ is the integral gain for high order harmonic, and $h=$ $3,5,7, \ldots$..

However, a simple PR controller is effective for a specific harmonic component. If it is to be valid for different orders of harmonic components orders, the transfer function in (2) becomes much more complicated and a long execution time is required.

On the other hand, it is known that a repetitive control is one of the specific control schemes for which the objective is to remove the errors due to the fundamental and harmonics of the periodic inputs. So, a repetitive control strategy is added to the simple PR controller as a compensator for all of the harmonic components. Then, the transfer function of PR repetitive controllers is expressed as [16]:

$$
H_{P R}(s)=K_{P}+K_{I} \frac{s}{s^{2}+\omega^{2}}+K_{R E} \frac{e^{-s T}}{1-e^{-s T}}
$$

where $K_{R E}$ is the repetitive controller gain and $\mathrm{T}$ is the delay time.

The structure of a PR repetitive current controller is shown in Fig. 3. 


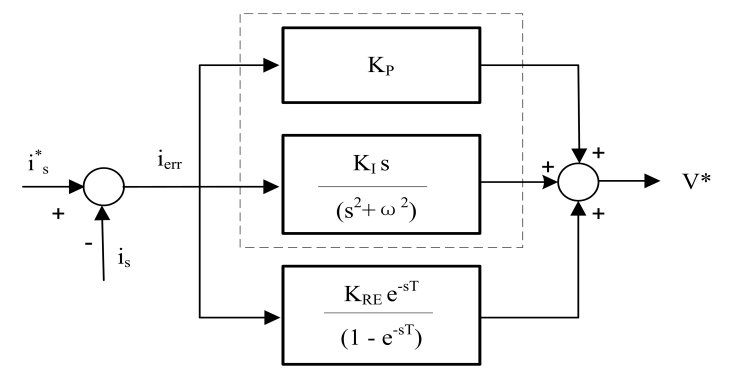

Fig. 3. PR repetitive current controllers.

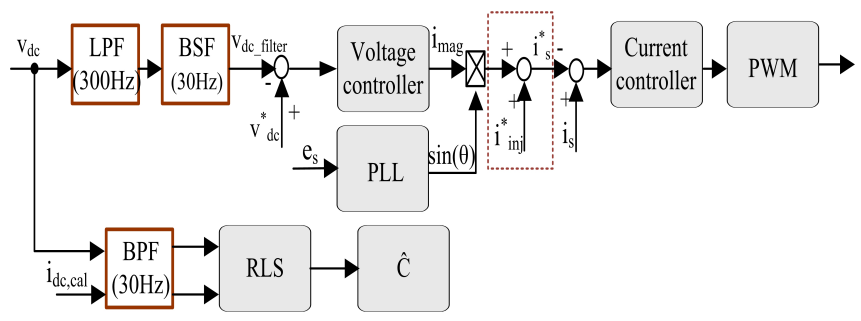

Fig. 4. Block diagram for estimating DC capacitance using current injection.

\section{CAPACITANCE ESTIMATION USING CURRENT INJECTION}

\section{A. AC Current Injection}

Let us consider the operation of a single-phase AC/DC PWM converter in the steady state under the no-load condition. In this condition, it is difficult to obtain any information for capacitance estimation. So, it is necessary to inject a particular signal to excite the system. For this propose, a regulated AC current with a low frequency is injected into the input side of the AC/DC PWM converter, which is expressed as:

$$
i_{i n j}^{*}=5 \sin (2 \pi \times 30 t) .
$$

The current level injected is determined considering the allowable ripple current of the capacitor and the frequency of the injected current is chosen considering the magnitude of the induced AC voltage component in the DC-link voltage. If it is too high, the induced voltage signal becomes too low, and vice versa. This information on the $\mathrm{AC}$ current and voltage components in a DC-link capacitor is used to calculate the capacitance at the last stage.

Fig. 4 shows a block diagram of the capacitance estimation in the case of current injection.

\section{B. Reconstruction of the DC- link Current}

In the proposed estimation method, the information for the DC-link current $\left(i_{d c}\right)$ needs to be known. For this purpose, however, it is not efficient to employ an additional DC current sensor. Therefore, instead of direct measurement of the DC-link current, reconstruction of its waveform can be implemented by using the gating time and the phase current. The DC-link current $i_{d c}$, can be calculated by the switching functions $\left(S_{a}, S_{b}\right)$ as [11]:

$$
i_{d c}=S_{a} i_{a s}+S_{b} i_{b s}
$$

where the switching functions mean ' 1 ' or ' 0 ' when an upper switch turns on or off, respectively and $i_{a s}$ and $i_{b s}$ are the currents flowing into the legs $\mathrm{A}$ and $\mathrm{B}$ of a single-phase PWM converter as shown in Fig. 1. Instead, using gating times and input current $\left(i_{s}\right)$, the mean value of the DC-link current $\left(i_{d c, c a l}\right)$ for each sampling period can be calculated as:

$$
i_{d c, c a l}=\frac{T_{g a} i_{a s}+T_{g b} i_{b s}}{T_{\text {sampling }}}
$$

where $T_{g a}$ and $T_{g b}$ are the gating times for each leg of the converter and $T_{\text {sampling }}$ is the sampling time. Since the dead time effect of the IGBT switching devices can be compensated for, its influence on (6) can be ignored [11].

\section{RLS Method for Current Injection}

The capacitance of the DC-link capacitor, $C$, can be calculated from:

$$
i_{d c}=C \frac{d v_{d c}}{d t}=C v_{d c}^{\prime}
$$

where $v_{d c}$ is the DC-link voltage. The second-order band-pass filters are applied to (7) in order to extract the DC-link current and the voltage ripple components at the injected frequency such as:

$$
B P F\left[i_{d c}\right]=C \times B P F\left[v_{d c}^{\prime}\right]
$$

where ' $B P F[\cdot]$ ' represent the band-pass filtered quantity.

The RLS algorithm can minimize the least square cost function. The error cost function is expressed in a discrete domain as [17]:

$$
e^{2}(n)=\left[B P F\left[i_{d c}(n)\right]-\hat{C}(n) B P F\left[v_{d c}^{\prime}(n)\right]\right]^{2} .
$$

The parameter $\hat{C}(n)$ is updated to minimize the error cost function $e^{2}(n)$ at each sampling time. So, the RLS update of the parameter $\hat{C}(n)$ can be expressed as:

$$
\begin{aligned}
\hat{C}(n+1)= & \hat{C}(n)+\mu(n) B P F\left[v_{d c}^{\prime}\right] \\
& \times\left\{B P F\left[i_{d c}(n)\right]-\hat{C}(n) B P F\left[v_{d c}^{\prime}(n)\right]\right\}
\end{aligned}
$$

where $\mu(n)$ is an adjustment gain, which is chosen as a constant $\left(9.5 \times 10^{-8}\right)$.

\section{Digital Filter}

The DC-link voltage measured includes the switchingfrequency-related harmonic components. To eliminate the harmonic components, a second-order low-pass filter is used [18], for which the transfer function is expressed as:

$$
H_{L P F}(s)=\frac{K_{L P F} \cdot \omega_{L P F}^{2}}{s^{2}+\left(\omega_{L P F} / Q_{L P F}\right) s+\omega_{L P F}^{2}}
$$

where $K_{L P F}$ is the gain, $\omega_{L P F}$ is the cut-off frequency, and $Q_{L P F}$ is the quality factor.

The AC component in the DC-link voltage passing through the low-pass filters needs to be eliminated since the mean value of the DC-link voltage should be fed back into the voltage controller. Therefore, a second-order band-stop filter tuned at the injected frequency is used, and its transfer function is expressed as:

$$
H_{B S F}(s)=\frac{K_{B S F} \cdot\left(s^{2}+\omega_{B S F}^{2}\right)}{s^{2}+\left(\omega_{B S F} / Q_{B S F}\right) s+\omega_{B S F}^{2}}
$$




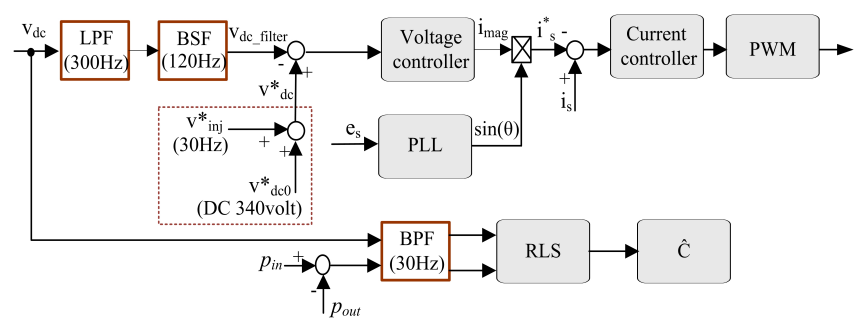

Fig. 5. Block diagram for estimating DC capacitance for using voltage injection.

where $K_{B S F}$ is the gain, $\omega_{B S F}$ is the cut-off frequency, and $Q_{B S F}$ is the quality factor.

To extract the AC components from the derivative of the measured DC voltage and the calculated DC-link current, a second-order band-pass filter tuned at the injected frequency is used, and its transfer function is expressed as:

$$
H_{B P F}(s)=\frac{K_{B P F} \cdot\left(\omega_{B P F} / Q_{B P F}\right) s}{s^{2}+\left(\omega_{B P F} / Q_{B P F}\right) s+\omega_{B P F}^{2}}
$$

where $K_{B P F}$ is the gain, $\omega_{B P F}$ is the cut-off frequency, and $Q_{B P F}$ is the quality factor.

\section{CAPACITANCE ESTIMATION USING VOLTAGE INJECTION}

\section{A. AC Voltage Injection}

In the current injection method described previously, the information on the DC-link current in (6) is required, which is complicated to calculate. Here, the voltage injection method can be used [12], which directly injects an exciting signal into the DC-link voltage. The injected AC voltage component is given by:

$$
v^{*} i n j=10 \sin (2 \pi \times 30 t)
$$

where the magnitude and frequency of the injected voltage are chosen in a way that is similar to the standard described previously. In the steady state, the DC-link voltage is constant except for the switching-frequency-related ripple components. After injecting the exciting signal, the DC-link voltage reference can be represented as: $V_{d c}^{*}=V_{d c 0}+10 \sin (2 \pi \cdot 30 t)[V]$. This specific AC voltage component can be easily extracted by digital filters and then used for the RLS algorithm.

Fig. 5 shows a block diagram of the capacitance estimation in the case of voltage injection.

\section{B. Power of a Capacitor}

From the converter circuit in Fig. 1, the capacitor power is expressed as:

$$
p_{\text {cap }}=p_{\text {in }}-p_{\text {out }}=\frac{C}{2} \frac{d v_{d c}^{2}}{d t}
$$

where $p_{\text {cap }}$ is the capacitor power, $p_{\text {in }}$ is equal to the input power of the converter if the converter loss is neglected, and $p_{\text {out }}$ is the output power delivered to the load. At no load, (15) can be rewritten as:

$$
p_{c a p}=p_{i n}=\frac{C}{2} \frac{d v_{d c}^{2}}{d t}
$$

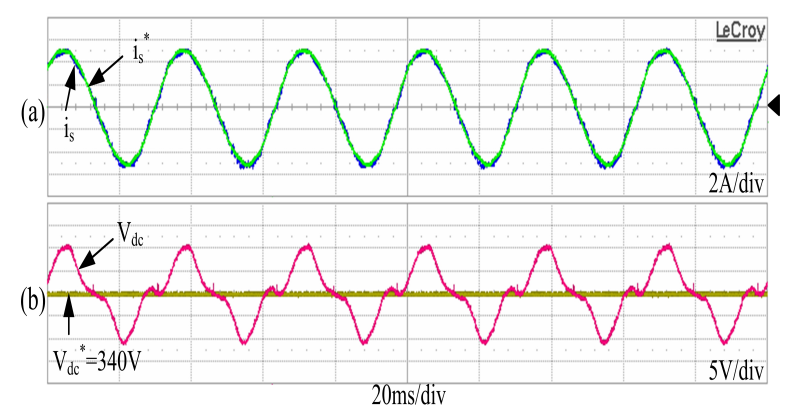

Fig. 6. Performance of current and voltage control in the case of current injection. (a) Source currents $\left(i_{s}\right.$ : actual, $i_{s}^{*}$ : reference). (b) DC-link voltages $\left(V_{d c}\right.$ : actual, $V_{d c}^{*}:$ reference).

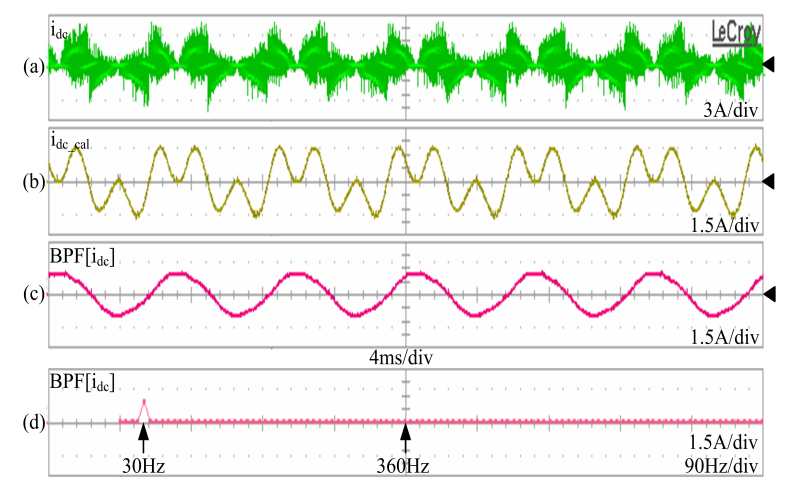

Fig. 7. DC-link currents. (a) Measured by probe. (b) Calculated ( $\left.i_{d c_{-} c a l}\right)$. (c) Band-pass filtered (BPF $\left.\left[i_{d c}\right]\right)$. (d) Harmonic spectrum of (c).

The instantaneous input power of the converter is calculated as:

$$
p_{\text {in }}=e_{s} i_{s}
$$

where $e_{s}$ is the source voltage and $i_{s}$ is the input current.

\section{RLS Method for Voltage Injection}

Applying the band-pass filter to both sides in (16) yields:

$$
B P F\left[p_{c a p}\right]=C \times B P F\left[\frac{1}{2} \frac{d v_{d c}^{2}}{d t}\right] .
$$

From (18), the RLS update of the parameter $\hat{C}(n)$ is given as [11]:

$$
\begin{aligned}
\hat{C}(n+1) & =\hat{C}(n)+\mu(n) B P F\left[\frac{1}{2} \frac{d v_{d c}^{2}}{d t}\right][n] \\
& \times\left\{B P F\left[p_{c a p}(n)\right]-\hat{C}(n) B P F\left[\frac{1}{2} \frac{d v_{d c}^{2}}{d t}\right][n]\right\}
\end{aligned}
$$

where $\mu(n)$ is an adjustment gain, which is chosen as a constant $\left(9.5 \times 10^{-13}\right)$.

\section{EXPERIMENTAL RESULTS}

To verify the effectiveness of the proposed scheme, experiments were carried out for a single-phase IBGT PWM AC/DC converter. A full verification of the simulation results shown in [19] is provided experimentally in this paper. The parameters of the PWM converter system, digital filters and controllers are listed in Table 1, 2 and 3, respectively. 


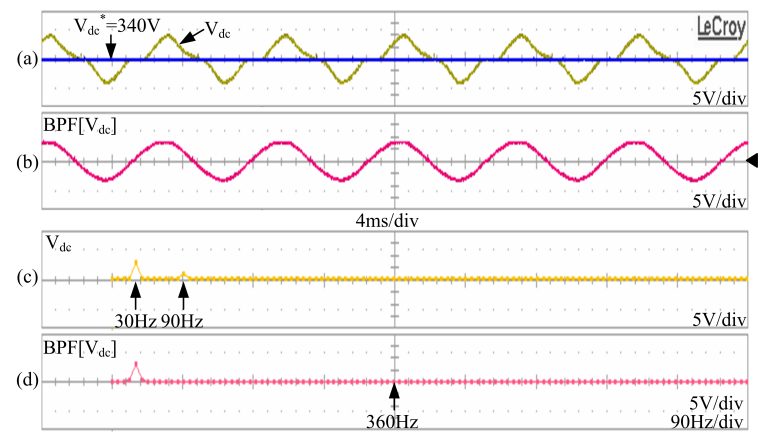

Fig. 8. DC-link voltages. (a) Measured. (b) Band-pass filtered $\left(B P F\left[V_{d c}\right]\right)$. (c) Harmonic spectrum of (a). (d) Harmonic spectrum of (b).

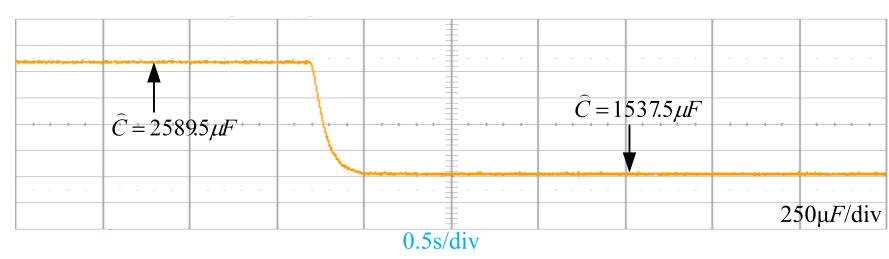

Fig. 9. Estimation performance in the case of abrupt change of capacitance.

From Fig. 6 to Fig. 9, the experiment results of the AC current injections are shown. Fig. 6(a) shows the source currents in the no load condition in which the actual value follows its reference well. Fig. 6(b) shows the DC-link voltage, which contains the same frequency component as the injected current.

TABLE I

PWM CONVERTER PARAMETERS

\begin{tabular}{|l|c|}
\hline \multicolumn{1}{|c|}{ Parameters } & Value \\
\hline Power rating & $3[\mathrm{~kW}]$ \\
\hline Input AC voltage & $220\left[V_{r m s}\right]$ \\
\hline Input boost inductance & $2.75[\mathrm{mH}]$ \\
\hline Line resistance & $0.06[\Omega]$ \\
\hline Switching frequency & $5[\mathrm{kHz}]$ \\
\hline DC-link voltage & $340[\mathrm{~V}]$ \\
\hline Sampling time & $100 \mu \mathrm{s}$ \\
\hline
\end{tabular}

TABLE II

FILTER PARAMETERS

\begin{tabular}{|c|c|c|c|}
\hline Filter Type & Gain & $\begin{array}{l}\text { Quality } \\
\text { factor }\end{array}$ & $\begin{array}{c}\text { Cut-off } \\
\text { Frequency }\end{array}$ \\
\hline $\begin{array}{l}\text { Second-order } \\
\text { low-pass filter }\end{array}$ & $K_{L P F}=1$ & $Q_{L P F}=2$ & $f_{L P F}=300[\mathrm{~Hz}]$ \\
\hline \multirow{2}{*}{$\begin{array}{l}\text { Second-order } \\
\text { band-stop filter }\end{array}$} & \multirow{2}{*}{$K_{B S F}=1$} & \multirow{2}{*}{$Q_{B S F}=2$} & $\begin{array}{c}f_{B S F}=30[\mathrm{~Hz}] \text { for } \\
\text { current injection }\end{array}$ \\
\hline & & & $\begin{array}{c}f_{B S F}=120[\mathrm{~Hz}] \text { for } \\
\text { voltabe injection }\end{array}$ \\
\hline $\begin{array}{c}\text { Second-order } \\
\text { band-pass filter }\end{array}$ & $K_{B P F}=1$ & $Q_{B P F}=2$ & $f_{B P F}=30[\mathrm{~Hz}]$ \\
\hline
\end{tabular}

Fig. 7 shows the DC-link currents, where Fig. 7(a) is the waveform measured by a current probe. Fig. 7(b) is the current waveform calculated in (3), Fig. 7(c) is the band-pass filtered output of (b), and Fig. 7(d) shows the harmonic spectrum of (c). Only a $30[\mathrm{~Hz}]$-frequency component exists.
TABLE III

CONTROLLER PARAMETERS

\begin{tabular}{|c|l|}
\hline Controller & \multicolumn{1}{|c|}{ Parameters } \\
\hline \multirow{2}{*}{ Voltage controller } & $K_{v p}=0.255$ \\
\cline { 2 - 2 } & $K_{v I}=18$ \\
\hline \multirow{3}{*}{ Current controller } & $K_{P}=27$ \\
\cline { 2 - 2 } & $K_{I}=1200$ \\
\cline { 2 - 2 } & $K_{R E}=0.5$ \\
\hline
\end{tabular}

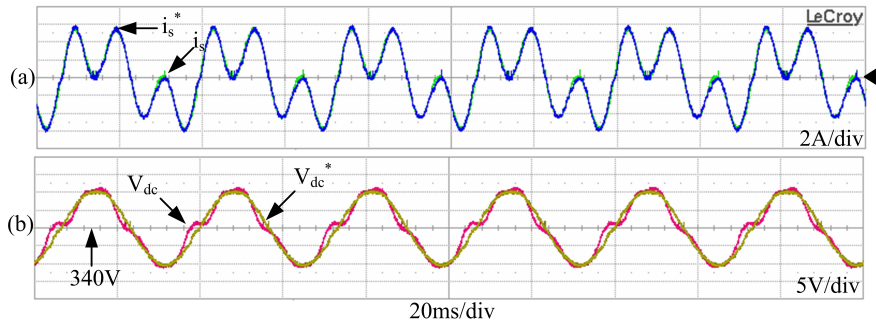

Fig. 10. Performance of current and voltage controllers for voltage injection method. (a) Source currents $\left(i_{s}^{*}\right.$ : reference, $i_{s}$ : actual). (b) DC-link voltages $\left(V_{d c}^{*}\right.$ : reference, $V_{d c}$ : actual).

Fig. 8 shows the DC-link voltages, where Fig. 8(a) shows the actual value and its reference, Fig. 8(b) illustrates the induced voltage component extracted by the band-pass filter, and Fig. 8(c) and (d) illustrate the harmonic spectrum of (a) and (b), respectively. The former includes $30[\mathrm{~Hz}]$ and $90[\mathrm{~Hz}]-$ frequency components, while, the latter contains only $30[\mathrm{~Hz}]-$ frequency component.

Fig. 9 shows the capacitance estimated in the case of an abrupt change in the capacitance, where the sudden change of capacitance has been made by disconnecting a capacitor of $C_{1}(1,046[\mu \mathrm{F}])$ while it is being operated with a capacitor of $C_{2}(1,550[\mu \mathrm{F}])$ in parallel. The capacitance data are listed in table 4 . The estimation error is about $0.25 \%-0.81 \%$, which is enough good for the diagnosis of capacitor deterioration.

In Fig. $10-13$, the experimental results in the case of $\mathrm{AC}$ voltage injection are illustrated. Fig. 10(a) and (b) show the source current and the DC-link voltage in the no-load condition, respectively, in which its reference is given by $V_{d c}^{*}=340+10 \sin (2 \pi \cdot 30 t)[V]$. The actual value deviated a little from the injected voltage reference since it includes higher frequency components $(90[\mathrm{~Hz}]$ and $150[\mathrm{~Hz}])$ which result from the frequency modulation effect [20].

Fig. 11(a) and (b) show the DC-link voltage measured and its $30[\mathrm{~Hz}]-$ frequency component through the band-pass filter, respectively. Fig. 11(c) and (d) show the harmonic spectra of (a) and (b), respectively. The $90[\mathrm{~Hz}]$ and $150[\mathrm{~Hz}]$-frequency components have been filtered out by the band-pass filter and only a $30[\mathrm{~Hz}]$-frequency component remains.

Fig. 12 shows the capacitor power, where Fig. 12(a) and (b) illustrate the calculated power from the source voltage and the band-pass filtered voltage, respectively. The corresponding harmonic spectra without and with filtering are shown in Fig. 12(c) and (d), respectively. It is clearly seen that frequency components higher than $30[\mathrm{~Hz}]$ have been eliminated.

Fig. 13 shows the capacitance estimated during an abrupt variation in the capacitance. Fig. 13(a) shows the filtered value of the DC-link ripple voltage and Fig. 13(b) shows the band- 


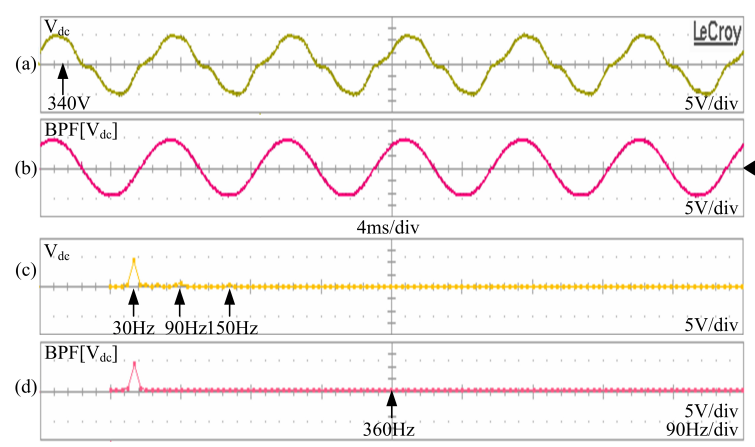

Fig. 11. DC-link voltages. (a) DC-link voltage ( $V_{d c}$ : actual voltage). (b) Band-pass filtered $\left(B P F\left[V_{d c}\right]\right)$. (c) Harmonic spectrum of (a). (d) Harmonic spectrum of (b).

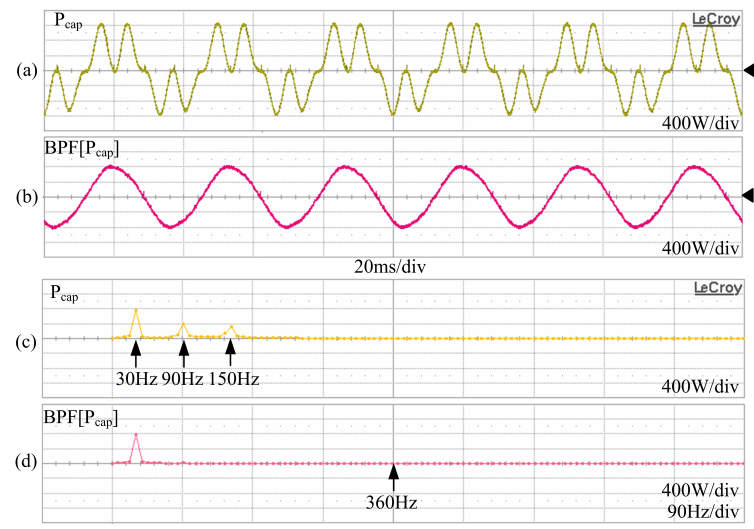

Fig. 12. Capacitor power. (a) Calculated capacitor power. $\left(P_{c a p}\right)$. (b) Band-pass filtered (BPF[P $\left.\left[P_{c a p}\right]\right)$. (c) Harmonic spectrum of (a). (d) Harmonic spectrum of (b).

pass filtered value of the capacitor power. As shown in (c), the estimated performance, which is shown in table IV, is as good as in the current injection method in the same case of an abrupt change in capacitance.

When comparing the two injection methods, it can be seen that both methods have high accuracy when it comes to capacitor estimation. However, the voltage injection method is better than the current injection method since it avoids calculation error.

\section{CONCLUSIONS}

In this paper, a new capacitance estimation schemes for single-phase AC/DC PWM converters has been proposed. Based on injecting a controlled $\mathrm{AC}$ current component (or a controlled $\mathrm{AC}$ voltage component), the capacitance value is estimated precisely less than $0.85 \%$ by signal processing. By this method, a DC electrolytic capacitor can be diagnosed online against its deterioration without any additional hardware. The proposed algorithm can be used effectively in single-phase grid-tie inverters for renewable energy conversion systems such as photovoltaic (PV) and fuel cells as well as UPS systems.

\section{ACKNOWLEDGMENT}

This research was supported by the Yeungman university research grants in 2008.

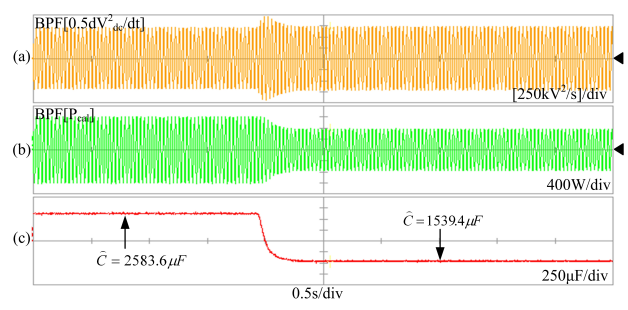

Fig. 13. Capacitance estimation at an abrupt variation of C. (a) Band-pass filtered $\left(B P F\left[0.5 d V_{d c}^{2} / d t\right]\right)$. (b) Band-pass filtered $\left(B P F\left[P_{c a p}\right]\right)$. (c) Estimated capacitance.

TABLE IV

CAPACITOR PARAMETERS

\begin{tabular}{|c|c|c|c|}
\hline Status Parameters & $C 1(\mu F)$ & $C 2(\mu F)$ & $C 1+C 2(\mu F)$ \\
\hline Nominal & 1,000 & 1,500 & 2,500 \\
\hline $\begin{array}{c}\text { Measured } \\
\text { (LCR meter) }\end{array}$ & 1,046 & 1,550 & 2,596 \\
\hline $\begin{array}{c}\text { Estimated } \\
\text { (current injection) }\end{array}$ & - & 1537.5 & 2589.5 \\
\hline Error & - & $0.81 \%$ & $0.25 \%$ \\
\hline $\begin{array}{c}\text { Estimated } \\
\text { (voltage injection) }\end{array}$ & - & 1539.4 & 2583.6 \\
\hline Error & - & $0.68 \%$ & $0.48 \%$ \\
\hline
\end{tabular}

\section{REFERENCES}

[1] M. F. Schonardie and D. C. Martins, "Solar grid-connected threephase system with active and reactive power control and input voltage clamped," in Proc. IEEE Electronics, Circuits and Systems Conf., pp. 463-466, Dec. 2007.

[2] J.-P. Lee, B.-D. Min, T.-J. Kim, D.-W. Yoo, and J.-Y. Yoo, "Design and control of novel topology for photovoltaic DC/DC converter with high efficiency under wide load ranges," Journal of Power Electronics. Vol.9, No.2, pp. 300-307, Mar. 2009.

[3] K.-W. Lee, M.-C. Kim, J.-H. Yoon, S.-B. Lee, and J.-Y. Yoo, "Condition monitoring of DC-link electrolytic capacitors in adjustable speed drives," IEEE Trans. Ind. Applicat., Vol.44, No.5, pp. 1606-1613, Sep./Oct. 2008.

[4] M. L. Gasperi, "Life prediction modeling of bus capacitors in AC Variable frequency drives," IEEE Trans. Ind. Applicat., Vol.41, No.6, pp. 1430-1435, Nov./Dec. 2005.

[5] A. Riz, D. Fodor, O. Klug, and Z. Karaffy, "Inner gas pressure measurement based life-span estimation of electrolytic capacitors," in Proc. IEEE Power Electronics and Motion Control Conf., pp. 20962101, Sep., 2008.

[6] K. Harada, A. Katsuki, and M. Fujiwara, "Use of ESR for deterioration diagnosis of electrolytic capacitor," IEEE Trans. Power Electron., Vol.8, No.4, pp. 355-361, Oct. 1993.

[7] Y.-M. Chen, H.-C. Wu, M.-W. Chou, and K.-Y. Lee, "Online failure prediction of the electrolytic capacitor for LC filter of switching mode power converters," IEEE Trans. Ind. Electron., Vol.55, No.1, pp. 400406, Jan. 2008

[8] E. C. Aeloza, J. H. Kim, P. Ruminot, and P. Enjeti, "A real time method to estimate electrolytic capacitor condition in PWM adjustable speed drives and uninterrupted power supplies," in Proc. IEEE Power Electronics Spec. Conf., pp. 2867-2872, Jun. 2005.

[9] K.-W. Lee, Myungchul Kim, Jangho Yoon, S.-B. Lee, and J.-Y. Yoo, "Condition monitoring of DC-link electrolytic capacitors in adjustable speed drives," IEEE Trans. Ind. Applicat., Vol.44, No.5, pp. 1606-1613, Sep./Oct. 2008.

[10] H. Ma and L. Wang, "Fault diagnosis and failure prediction of aluminum electrolytic capacitors in power electronics converters," in Proc. IEEE Ind. Electronics Society Conf., pp. 842-847, Nov. 2005.

[11] D.-C. Lee, K.-J. Lee, S.-K. Jang, and J.-W. Choi, "Online capacitance estimation of DC-link electrolytic capacitors for three-phase AC/DC/AC PWM converters using recursive least squares method," IEE Proc. Electric Power Applicat., Vol.152, No.6, pp. 1503-1508, Nov. 2005.

[12] A. G. Abo-Khalil and D.-C. Lee, "DC-link capacitance estimation in AC/DC/AC PWM converters using voltage injection", IEEE Trans. Ind. Applicat., Vol.44, No.5, pp. 1631-1637, Sep./Oct. 2008. 
[13] S. A. Oliveira da Silva, R. Novochadlo, and R.A. Modesto, "Singlephase PLL structure using modified $\mathrm{p}-\mathrm{q}$ theory for utility connected systems," in Proc. IEEE Power Electron. Spec. Conf., pp. 4706-4711, Jun. 2008.

[14] R. Teodorescu, F. Blaabjerg, M. Liserre, and P.C. Loh, "Proportionalresonant controllers and filters for grid-connected voltage-source converters," IEE Proc. Electric Power Applicat., Vol.153, No.5, pp. 750-762, Sep. 2006.

[15] A. Timbus, M. Liserre, R. Teodorescu, P. Rodriguez, and F. Blaabjerg, "Evaluation of current controllers for distributed power generation systems," IEEE Trans. Power Electronics, Vol.24, No.3, pp. 654-664, Mar. 2009.

[16] D.-G. Kim, J.-W. Choi, and H.-G. Kim, "Current control method of distribution static compensator considering non-linear load," Trans. of KIEE, Vol.58, No.7, pp. 1342-1348, Jul. 2009.

[17] S. Haykin and B. Widrow, Least-Mean-Square Adaptive Filters, Wiley Publishing, 2003.

[18] R. Chassaing, Digital singal processing, John Wiley \& Sons Inc., 1999.

[19] X.-S. Pu, T. H. Nguyen, D.-C. Lee, and S.-G. Lee, "Capacitance estimation of DC-link capacitors for single-phase PWM converters," in Proc. IEEE Power Electronics and Motion Control Conf., pp. 1656-1661, May 2009.

[20] W. P. Torres, A. V. Oppenheim, and R. R. Rosales, "Generalized frequency modulation," IEEE Trans. Circuits and Systems, Vol.48, No.12, pp. 1405-1412, Dec. 2001.

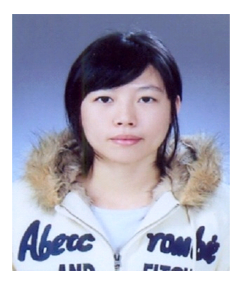

Xing-Si Pu was born in Kai Yuan city of Yun Nan province, China, in 1986. In 2008, she received her B.S from both Bei Hua University, China and Yeungnam University, Korea, respectively. She is currently working toward her M.S. in the Department of Electrical Engineering, Yeungnam University, Korea.

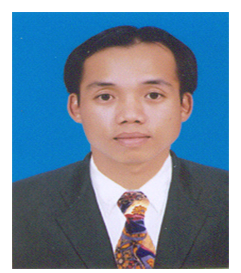

Thanh Hai Nguyen was born in Dong Thap, Viet Nam on October 7, 1980. He received his B.S. from the Technology University of Ho Chi Minh City, in 2003 and his M.S in the Department of Electrical Engineering, Yeungnam University, Korea in 2010 where, he is currently working toward his Ph.D. He was an assistant lecturer in the College of Technology, Can Tho University, Viet Nam in 2003. His research interests power generation. include power converters, machine drives, and wind

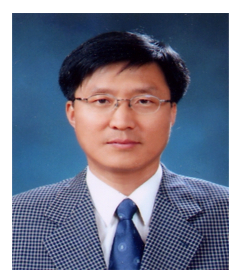

Dong-Choon Lee received his B.S., M.S., and Ph.D. in Electrical Engineering from Seoul National University, Seoul, Korea, in 1985, 1987, and 1993, respectively. He was a Research Engineer with Daewoo Heavy Industry from 1987 to 1988 . Since 1994, he has been a faculty member in the Department of Electrical Engineering, Yeungnam University, Gyeongbuk, Korea. Currently, he is a full Professor and a Vice Dean of Academic Affairs, College of Engineering. In addition, he is serving as a Publication Editor, Journal of Power Electronics, the Korean Institute of Power Electronics, Korea. As a Visiting Scholar, he joined the Power Quality Laboratory, Texas A\&M University, College Station in 1998, the Electrical Drive Center, University of Nottingham, U.K. in 2001, and the Wisconsin Electric Machines \& Power Electronic Consortium, University of Wisconsin, Madison in 2004. His research interests include ac machine drives, control of power converters, wind power generation, and power quality.

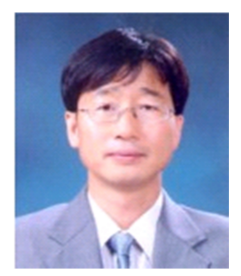

Suk-Gyu Lee received his B.S. and M.S. in Electrical Engineering from Seoul National University, Korea, in 1979 and 1981, respectively and his Ph.D in Electrical Engineering from the University of California, Los Angeles, USA in 1990. Currently he is a Professor in the Department of Electrical Engineering, Yeungnam University, Korea. His research interests include robotics, motor control, and intelligent control. 